\title{
RAPID AND ACCURATE HPLC-DAD METHOD FOR THE DETERMINATION OF THE HERBICIDE BISPYRIBAC-SODIUM IN SURFACE WATER, AND ITS VALIDATION
}

\author{
Márcia H. S. Kurz, Fábio F. Gonçalves, Samile Martel, Martha B. Adaime e Renato Zanella* \\ Departamento de Química, Universidade Federal de Santa Maria, 97105-900 Santa Maria - RS, Brasil \\ Sérgio L. de O. Machado \\ Departamento de Defesa-Fitossanitária, Universidade Federal de Santa Maria, 97105-900 Santa Maria - RS, Brasil \\ Ednei G. Primel \\ Departamento de Química, Fundação Universidade Federal do Rio Grande, 96201-900 Rio Grande - RS, Brasil
}

Recebido em 3/7/08; aceito em 23/1/09; publicado na web em 14/7/09

\begin{abstract}
A new method is described for the determination of the herbicide bispyribac-sodium in surface water, especially from river and irrigated rice water samples. The method involves extraction in solid phase and quantification by high performance liquid chromatography with diode array detection (HPLC-DAD). After optimization of the extraction and separation parameters, the method was validated. The method presented average recoveries of 101.3 and $97.7 \%$, under repeatability and intermediate precision conditions, respectively, with adequate precision (RSD from 0.9 to $7.5 \%$ ). The method was applied for the determination of bispyribac-sodium in surface water samples with a limit of detection of $0.1 \mu \mathrm{g} \mathrm{L}{ }^{-1}$.
\end{abstract}

Keywords: pesticide; river water; irrigation water.

\section{INTRODUCTION}

Rice farming, especially the irrigated, has great social and economic importance in several countries like Brazil. Irrigated farming for food production is the agricultural practice that most contributes to the deviation of water from its natural courses. Scarcity of water resources, which is occurring on a world-wide level, as well as the use of a large quantity of water, which is partially returned to its natural sources, makes irrigated rice farming a serious concern in terms of possible consequences for the environment, both in quantity and quality of water.

Rice production in the State of Rio Grande do Sul represents more than $58 \%$ of the Brazilian rice production. Productivity levels in Brazil are high, reaching an average value of $6.0 \mathrm{t} \mathrm{ha}^{-1}$ in the 2004/05 crop, similar to that obtained in countries with a tradition in irrigated rice farming, such as the United States, Australia and Japan. However, this high productivity is associated with the intense use of fertilizers and pesticides. ${ }^{1}$

Bispyribac-sodium, sodium 2,6-bis[(4,6-dimethoxy-2-pyrimidinyl)oxy]benzoate (Figure 1) is a herbicide registered in Brazil for use in irrigated rice farming and is also recommended for rice farming in other countries such as the USA. It is indicated for the postemergence control of cyperaceous grasses and some dicotyledonous grasses and is sold commercially as a suspension concentrate under the name of Nominee ${ }^{\circledR} 400 \mathrm{SC}$, with a recommended application rate of 40 to $50 \mathrm{~g}$ active ingredient $\mathrm{ha}^{-1}$. This herbicide belongs to the toxicological class II, considered very toxic.

The compound has acidic characteristics, with a pKa of 3.05, is highly soluble in water $\left(73300 \mathrm{mg} \mathrm{L}^{-1}\right)$, presents a $\mathrm{K}_{\mathrm{oc}}$ of 5000 $\mathrm{cm}^{3} \mathrm{~g}^{-1}$ and a half-life in soil of less than 10 days., ${ }^{2,3}$ The herbicide presents a lethal dose of $3524 \mathrm{mg} \mathrm{kg}^{-1}$ when applied orally in rats, and presents $\mathrm{CL}_{50}$ for trout $(96 \mathrm{~h})>100 \mathrm{mg} \mathrm{L}^{-1}$ and $\mathrm{CL}_{50}$ for Daphnia $(48 \mathrm{~h})>100 \mathrm{mg} \mathrm{L}^{-1} \cdot 4,5$

During many years, the analysis of pesticides in environmental samples has attracted attention due to the wide use of such compounds, as well as their environmental impact. The European Union establishes strict limits for pesticides in water for human

*e-mail: rzanella@base.ufsm.br<smiles>COc1cc(OC)nc(Oc2cccc(Oc3nc(OC)cc(OC)n3)c2C(N)=O)n1</smiles>

Figure 1. Chemical structure of the herbicide bispyribac-sodium

consumption, a level of $0.1 \mu \mathrm{g} \mathrm{L}^{-1}$ for individual pesticides and of $0.5 \mu \mathrm{g} \mathrm{L}^{-1}$ for the total of pesticides. In the case of surface water for human consumption the maximum levels permitted are $1 \mu \mathrm{g} \mathrm{L}^{-1}$ for individual pesticides and $5 \mu \mathrm{g} \mathrm{L}^{-1}$ for the total of pesticides. ${ }^{6}$ Brazilian and American legislations establish maximum limits for pesticides in drinking and environmental water, but bispyribacsodium is not included.

The high level of water purity imposed by regulating agencies requires the development of analytical methods that are sensitive, selective, accurate and precise for quantitative determinations of pesticides compatible with the growing level of exigency. ${ }^{7}$

Recent publications show that there is a tendency to utilize sophisticated techniques such as GC-MS and LC-MS in the determination of pesticide residues in water. ${ }^{7-9}$ However, methods that utilize HPLC with ultraviolet absorbance or diode array detection are widely used $^{10-14}$ and are fitting for the analysis of herbicides in water, without requiring an elevated investment in instrumentation.

The sample preparation by solid phase extraction (SPE) was introduced in the 1970's and had good commercial progress with the development of cartridges and disks for extraction. An important step in this technique is the selection of the sorbent, where C18 and copolymers of styrene-divinylbenzene are the most frequently used. SPE is the most common technique for the determination of pesticide residues by chromatographic methods in aqueous samples. ${ }^{7-15}$

The objectives of this study were: to develop and validate a simple and quick method, utilizing SPE and HPLC-DAD, to quantify the herbicide bispyribac-sodium in samples from surface water, especially those with high organic content, like river water and irrigated rice water. 


\section{EXPERIMENTAL}

\section{Chemicals}

Standard of bispyribac-sodium with $99 \%$ of purity from Dr. Ehrenstorfer (Germany) was used. The stock solution was prepared in acetonitrile at a concentration of $1000 \mathrm{mg} \mathrm{L}^{-1}$ and kept at $-16{ }^{\circ} \mathrm{C}$. The analytical solutions were prepared by dilution of this stock solution in the mobile phase and were renewed each two weeks. The SPE cartridges Strata C18-E $500 \mathrm{mg} / 3 \mathrm{~mL}$ and Strata-X $200 \mathrm{mg} / 6$ $\mathrm{mL}$ (Phenomenex, U.S.A.) were evaluated. The following were also used: acetonitrile, dichloromethane and methanol, all Nanograde ${ }^{\circledR}$ degree (Mallinckrodt, U.S.A.), water purified in the system DirectQ UV3 ${ }^{\circledR}$ (resistivity $18.2 \mathrm{M} \Omega \mathrm{cm}$, Millipore, USA), and phosphoric acid analytical degree $85 \%$ (Merck, Brazil).

\section{Instrumentation}

Liquid chromatograph from Varian (Palo Alto, USA) with a solvent delivery system model 9002, diode array detector (DAD) ProStar 335, system of data acquisition Star Workstation 6.0, analytical column Synergi $4 \mu$ Fusion RP-80 (250 x 4.6 mm i.d.; 4 $\mu \mathrm{m})$ and guard-column of the same material $(4 \times 3 \mathrm{~mm})$, both from Phenomenex (Torrance, USA) was used. The mobile phase consisted of a mixture of acetonitrile:water (55:45, v/v), pH 2.0 adjusted with phosphoric acid. A flow-rate of $1.0 \mathrm{~mL} \mathrm{~min}^{-1}$ was used, with $20 \mu \mathrm{L}$ of injection and detection at $247 \mathrm{~nm}$. Whenever necessary, UV spectra were recorded within a range of 200 to $400 \mathrm{~nm}$.

\section{Extraction procedure}

The SPE extraction procedure was evaluated considering the $\mathrm{pH}$ of the sample, volume and solvent of elution, and volume of sample passed through the cartridge (breakthrough volume). Two different sorbents were tested: octadecylsilane (Strata C18-E) and polymeric Strata-X (copolymer of styrene-divinylbenzene with modified surface).

The volume of the sample was chosen in function of the breakthrough volume, which occurs when the pesticides are not strongly retained by the sorbent or when the capacity of the sorbent in the cartridge is exceeded. ${ }^{16}$ Different volumes varying from 50 up to $500 \mathrm{~mL}$ were studied, with a constant analyte mass of $0.1 \mu \mathrm{g}$ transferred to the cartridges. Compounds that can ionize are only adequately retained in $\mathrm{C} 18$ if they are in their neutral form. Thus, in the preconcentration of bispyribac-sodium the sample was adjusted at $\mathrm{pH} 2.0$ with phosphoric acid. The samples, placed in volumetric flasks, were transferred through polytetrafluorethylene tubes to SPE cartridges placed in a SPE manifold. The cartridges were eluted, the solvent evaporated, the final dried extract was reconstituted in mobile phase and quantified by HPLC-DAD.

\section{Method validation}

Once defined the best conditions for the analysis of the bispyribacsodium, the validation of the method was carried out, according to parameters described as follows.

\section{Calibration curve}

The analytical curve was obtained by triplicate analysis of each bispyribac-sodium standard solutions at seven concentration levels ranged between 0.06 and $5.0 \mathrm{mg} \mathrm{L}^{-1}$.

Limit of detection (LOD) and quantification (LOQ)

In this study LOD and LOQ were determined considering the LOD as 3 times the baseline noise and the LOQ as the concentration that produced a relation signal to baseline noise of 10 , in a time close to the retention time of the analyte. ${ }^{17}$

\section{Precision (repeatability and intermediate precision) and accuracy (recovery)}

The precision was evaluated in terms of repeatability and intermediate precision and was expressed as relative standard deviation (RSD). ${ }^{18}$ The precision of the method, in terms of repeatability $\left(\mathrm{RSD}_{\mathrm{r}}\right)$ was obtained by carrying out the extraction and analysis of fortified samples. Each spike level was extracted in five replicates and each extract injected three times. To evaluate the intermediate precision $\left(\mathrm{RSD}_{\mathrm{ip}}\right)$ of the method, different days and operators were used.

In pesticide residue analysis, the accuracy normally is evaluated by carrying out recovery assays. ${ }^{18}$ In this study, to evaluate the recovery of the method, analyses were carried out in five replicates of "blank" surface water samples spiked at three different levels $(0.5,2.5$ and $\left.5.0 \mu \mathrm{g} \mathrm{L}^{-1}\right)$. The recovery tests were carried out on five replicates at each spike level. Results are the average from three injections.

For environmental and food samples, accuracy and precision depends greatly on the sample matrix, the analyte concentration level and the method of analysis. In this study, the SANCO recommendations that the recoveries must be within the range 70 and $120 \%$, with RSD below $20 \%$, were followed. ${ }^{18}$

\section{Application of the method}

The developed method was applied in a dissipation study carried out in experimental fields in the agricultural year of 2006/2007. The water samples were collected up to 60 days after the application of the herbicide at the recommended dose (50 $\mathrm{g}$ bispyribac-sodium ha $\left.{ }^{-1}\right)$.

The method was also successfully used for the determination of bispyribac-sodium in 40 water samples from rivers of the central region of the State of Rio Grande do Sul (Brazil), in the period between November 2006 and February 2007.

\section{RESULTS AND DISCUSSION}

\section{Chromatographic analysis}

The HPLC-DAD system proved to be a good option for the determination of bispyribac-sodium in real water samples, allowing analysis with good sensitivity and in a total time of $10 \mathrm{~min}$. Under the chosen chromatographic conditions, bispyribac-sodium showed a retention time $\left(t_{R}\right)$ of $9.9 \pm 0.1 \mathrm{~min}$. Typical chromatograms of a standard solution of the herbicide at $0.1 \mathrm{mg} \mathrm{L}^{-1}$, a "blank" surface water SPE extract and a "blank" surface water spiked at $0.5 \mu \mathrm{g} \mathrm{L}^{-1} \mathrm{SPE}$ extract are demonstrated in Figure 2, where it is possible to see that no interferences are present in the region of the retention time of bispyribac-sodium.

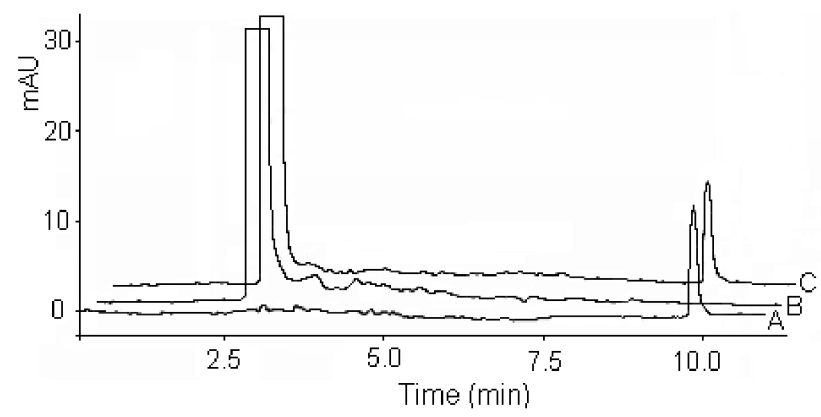

Figure 2. Typical chromatograms of (A) a standard solution of bispyribacsodium at $0.1 \mathrm{mg} \mathrm{L}^{-1},(B)$ a "blank" surface water and (C) a "blank" surface water spiked at $0.5 \mu \mathrm{g} L^{-1}\left(t_{R}\right.$ bispyribac-sodium $\left.=9.9 \mathrm{~min}\right)$ 


\section{SPE preconcentration step}

The results obtained for the method development stage are demonstrated as follows. According to Barceló and Hennion ${ }^{16}$ for acidic herbicides the $\mathrm{pH}$ must be below the $\mathrm{pKa}$, so that the most part of the compound remains in its non-ionized form. As the herbicide studied has a pKa value equal to $3.05,{ }^{4}$ the $\mathrm{pH}$ value chosen for the preconcentration step of bispyribac-sodium from water was 2.0 , because lower values could cause problems in relation to the stability of the sorbent. Sample volumes of $100 \mathrm{~mL}$ of water were spiked at a level of $5 \mu \mathrm{g} \mathrm{L} \mathrm{L}^{-1}$ and the $\mathrm{pH}$ was adjusted to 2.0. After the preconcentration step in SPE, elution with $2 \mathrm{~mL}$ of solvent, evaporation of the solvent and redissolution in 500 $\mu \mathrm{L}$ of mobile phase was performed. Table 1 presents the results obtained for recovery with different adsorbents and elution solvents.

Table 1. Recoveries obtained with different sorbents and different elution solvents

\begin{tabular}{lcc}
\hline \multirow{2}{*}{ Elution solvent } & \multicolumn{2}{c}{ Recovery $\pm(\%)$} \\
& C18 & Polymeric \\
\hline Dichloromethane:methanol 65:35 (v/v) & $93.8 \pm 7.7$ & $86.0 \pm 9.1$ \\
Dichloromethane:methanol 80:20 (v/v) & $71.8 \pm 9.4$ & $36.3 \pm 12.3$ \\
Dichloromethane:acetonitrile 50:50 (v/v) & $84.1 \pm 12.0$ & $90.0 \pm 11.5$ \\
\hline
\end{tabular}

Good results were obtained with both $\mathrm{C} 18$ and polymeric sorbents using a mixture of dichloromethane:methanol 65:35 (v/v) or dichloromethane:acetonitrile 50:50 (v/v) as eluent. However, as C18 is a more common sorbent and presented consistent good recovery, it was chosen for this method. As eluent, the mixture of dichloromethane:methanol $(65: 35, \mathrm{v} / \mathrm{v})$ provided the best results for C18. Pure methanol and acetonitrile were also tested as eluent, but they did not provide good recoveries. In SPE using sorbent C18, the solubility of compounds in the solvent is very important because many compounds have limited solubility in methanol or acetonitrile, being thus necessary a great elution volume. The addition of dichloromethane can increase the solubility of the analytes and help to give better contact with the sorbent, especially because traces of water may still be present in the cartridge. ${ }^{16}$

Defined the better sorbent and elution solvent, the breakthrough volume for the herbicide in cartridges with $\mathrm{C} 18$ was studied using spiked samples with volume from 50 to $500 \mathrm{~mL}$, where the absolute amount of the analyte remaining constant in $0.1 \mu \mathrm{g}$. The results are summarized in Table 2.

With a volume higher than $100 \mathrm{~mL}$, a considerable reduction in the recovery was observed. In SPE with sorbent $\mathrm{C} 18$, the breakthrough volume is a function of the hydrophobicity of the solute and the mass of the sorbent used. ${ }^{19}$ As the mass of the sorbent probably is

Table 2. Results for breakthrough volume of bispyribac-sodium in cartridges containing $500 \mathrm{mg}$ of $\mathrm{C} 18$

\begin{tabular}{lccc}
\hline $\begin{array}{l}\text { Sample volume } \\
(\mathrm{mL})\end{array}$ & $\begin{array}{c}\text { Concentration } \\
\left(\mu \mathrm{g} \mathrm{L}^{-1}\right)\end{array}$ & $\begin{array}{c}\text { Recovery } \\
(\%)\end{array}$ & $\begin{array}{c}\text { RSD } \\
(\%)\end{array}$ \\
\hline 50 & 2.0 & 106.0 & 11.9 \\
100 & 1.0 & 95.7 & 6.2 \\
150 & 0.7 & 85.9 & 9.9 \\
200 & 0.5 & 74.4 & 5.2 \\
250 & 0.4 & 65.3 & 7.4 \\
300 & 0.3 & 58.5 & 5.4 \\
500 & 0.2 & 41.7 & 7.1 \\
\hline
\end{tabular}

not a limiting factor, in this study we used cartridges with $500 \mathrm{mg}$ of sorbent and the results obtained are related to the fact that bispyribacsodium is not very hydrophobic, presenting a $\mathrm{K}_{\mathrm{ow}} \log \mathrm{P}$ value of -1.03 . Therefore, the volume of the sample used in the validation of the method was $100 \mathrm{~mL}$.

\section{The optimized extraction procedure}

The extraction of bispyribac-sodium start with the conditioning of the cartridge with $3 \mathrm{~mL}$ of methanol followed by $3 \mathrm{~mL}$ of purified water to remove the methanol excess and $3 \mathrm{~mL}$ of purified water adjusted to $\mathrm{pH}$ 2.0. Sample volumes of $100 \mathrm{~mL}$ of surface water adjusted to $\mathrm{pH}$ 2.0 were percolated through the adsorbent at circa $5 \mathrm{~mL} \mathrm{~min}^{-1}$. After the preconcentration stage, $3 \mathrm{~mL}$ of purified water was transferred to the cartridge to minimize any interference, followed by vacuum for $15 \mathrm{~min}$. In the sequence, the cartridge was eluted with two aliquots of $1.0 \mathrm{~mL}$ of the eluent mixture. The eluate was collected in a vial and the solvents were evaporated with a gentle stream of nitrogen. For the analysis by HPLC-DAD, $500 \mu \mathrm{L}$ of the mobile phase was used for the redissolution of the solid residue.

\section{Method validation}

\section{Calibration curve and linearity}

The equation of linear regression obtained for the seven concentration levels, each one injected three times, was: $y=$ $54.641 \mathrm{x}-0.2261$, where $\mathrm{y}=$ peak area, $\mathrm{x}=$ bispyribac-sodium concentration $\left(\mathrm{mg} \mathrm{L}^{-1}\right)$, with a correlation coefficient $(\mathrm{r})$ equal to 0.9998. From the analytical curve, the linearity of the method was evaluated, demonstrating a linear interval in the range of 0.06 to $5.0 \mathrm{mg} \mathrm{L}^{-1}$.

\section{Limit of detection (LOD) and quantification $(L O Q)$}

For the instrument, the LOD was $0.02 \mathrm{mg} \mathrm{L}^{-1}$ and the LOQ was $0.06 \mathrm{mg} \mathrm{L}^{-1}$. Considering a preconcentration factor of 200 times, the method LOD and LOQ were 0.1 and $0.3 \mu \mathrm{g} \mathrm{L}{ }^{-1}$, respectively, which are considered adequate for the control of residues of bispyribac-sodium in surface waters. The value of the method LOQ was below the maximum levels permitted for pesticides in surface waters, which are of $1 \mu \mathrm{g} \mathrm{L}^{-1}$ for individual pesticides and of $5 \mu \mathrm{g} \mathrm{L}^{-1}$ for total pesticides in waters that will be destined for human consumption after treatment. ${ }^{6}$

\section{Precision (repeatability and intermediate precision) and accuracy (recovery)}

Table 3 presents the results obtained for accuracy and precision for bispyribac-sodium in surface water. The accuracy obtained for bispyribac-sodium from within- and between-batch recoveries assays, at all concentration levels and conditions investigated, ranged from 93.3 to $95.9 \%$ and from 95.3 to $99.7 \%$, respectively. The average recovery was $96.2 \%$, which is very satisfactory. The method precision under repeatability $\left(\mathrm{RSD}_{\mathrm{r}}\right)$ conditions ranged from 4.6 to $7.0 \%$ and under intermediate precision $\left(\mathrm{RSD}_{\mathrm{ip}}\right)$ conditions ranged from 2.8 to $7.5 \%$. The results are fairly good for the concentration levels investigated. All the values obtained were within guideline requirements (recoveries: 70-120\%; relative standard deviation (RSD) below 20\%). ${ }^{18}$

\section{Analysis of real samples}

The developed method was applied in a dissipation study carried out in the Experimental fields of the Weed Science Department of the Federal University of Santa Maria in the agricultural year 2006/2007. In the analysis of this kind of water sample, the 
Table 3. Recovery, repeatability and intermediate precision for bispyribac-sodium in surface water spiked at three different levels

\begin{tabular}{lcccc}
\hline $\begin{array}{l}\text { Spiked level } \\
\left(\mu \mathrm{g} \mathrm{L}^{-1}\right)\end{array}$ & \multicolumn{2}{c}{ Within-batch } & \multicolumn{2}{c}{ Between-batch } \\
\hline 0.5 & Recovery $(\%)$ & RSD $_{\mathrm{r}}(\%)$ & Recovery $(\%)$ & RSD $_{\text {ip }}(\%)$ \\
2.5 & 93.3 & 4.6 & 99.7 & 7.5 \\
5.0 & 95.9 & 7.0 & 95.3 & 2.8 \\
\hline
\end{tabular}

(5 extractions and 3 injections each)

presence of organic substances, mainly fulvic and humic substances that are also retained in the SPE cartridges, results in extracts with a light yellowish coloration and the chromatograms present a peak of high intensity at the beginning of the chromatogram, but this peak did not interfere with the quantification of the herbicide bispyribac-sodium.

In this dissipation study, residues of bispyribac-sodium were found up to 21 days after application and the concentration at this time was of $0.3 \mu \mathrm{g} \mathrm{L} \mathrm{L}^{-1}$.

Concerning the 40 river water samples collected during the rice production season 2006/2007, period of the rice culture where part of the irrigation water is released to the environment, no detectable residues of bispyribac-sodium were observed in water samples from rivers located in the regions which produce rice. No interference from the sample matrix was observed, demonstrating the usefulness of the developed method.

\section{CONCLUSIONS}

The reversed-phase HPLC separation with DAD detection together with the preconcentration step accomplished by solid-phase extraction using $\mathrm{C} 18$ cartridges after adjustment of the sample $\mathrm{pH}$ to 2.0 enabled the determination of bispyribac-sodium with good accuracy, precision and detection and quantification limits. The effective LOD and LOQ in the surface water samples after preconcentration step were 0.1 and $0.3 \mu \mathrm{g} \mathrm{L}{ }^{-1}$, respectively. The method has proven to be efficient to follow the dissipation of bispyribac-sodium in irrigated rice water after the treatment of rice fields with this herbicide, as well as to monitor the herbicide in river water at levels around $0.1 \mu \mathrm{g} \mathrm{L} \mathrm{L}^{-1}$.

\section{ACKNOWLEDGMENTS}

The authors would like to thank Brazilian agencies FAPERGS, CNPq/CT-HIDRO and CAPES for financial support and fellowships.

\section{REFERENCES}

1. Baird, C.; Cann, M.; Environmental Chemistry, $3^{\text {rd }}$ ed., W. H. Freeman: New York, 2005, p. 313-400.

2. Vencill, W. K.; Herbicide Handbook, $8^{\text {th }}$ ed., Weed Science Society of America: Lawrence, 2002.

3. Ware, G. W.; The Pesticide Book, $4^{\text {th }}$ ed., Thomson Publications: Fresno, 1994.

4. Tomlin, C.; The e-Pesticide Manual, 13t ${ }^{\mathrm{h}}$ ed., Version 3.0., BCPC, Crop Protection Publication: Cambridge, UK, CD-ROM. 2003.

5. Environmental Protection Agency (EPA); Bispyribac-Sodium: Pesticide Tolerance Related Material, 2001, volume 66, number 181.

6. Kuster, M.; Alda, M. L.; Barceló, D.; Mass Spectrom. Rev. 2006, 25, 900.

7. Picó, Y.; Fernández, M.; Ruiz, M. J.; Font, G.; J. Biochem. Biophys. Methods 2007, 70, 117.

8. Richardson, S. D.; Anal. Chem. 2006, 78, 4021.

9. Soler, C.; Picó, Y.; Trends Anal. Chem. 2007, 26, 103.

10. Bezemer, E.; Rutan, S.; Anal. Chem. 2001, 73, 4403.

11. Chao, J.; Liu, J.; Jiang, G.; J. Chromatogr., A. 2002, 955, 183.

12. Liu, J.; Chao, J.; Jiang, G.; Cai, Y.; Liu, J.; J. Chromatogr., A 2003, 995, 21.

13. Zhu, Q. Z.; Degelmann, P.; Niessner, R.; Knopp, D.; Environ. Sci. Technol. 2002, 36, 5411.

14. Lagana, A.; Fago, C.; Marino, A.; Anal. Chem. 1998, 70, 121.

15. D'Archivio, A.; Fanelli, M.; Mazzeo, P.; Ruggieri, F.; Talanta 2007, $71,25$.

16. Barceló, D.; Hennion, M. C.; Trace determination of pesticides and their degradation products in water, $3^{\text {rd }}$ ed., Elsevier: Amsterdam, 1997, p. 542.

17. Bottoli, C. B. G.; Ribani, M.; Collins, C. H.; J. Chromatogr., A 2007, 1156, 201.

18. European Commission; Method Validation and Quality Control Procedures for Pesticide Residues Analysis in Food and Feed, SANCO/2007/3131, 2007.

19. Wells, M. J. M. In Solid-phase extraction: principles, techniques and applications; Simpson, N. J. K., ed.; Marcel Dekker: New York, 2000. 